\title{
$\bullet$ IJCRR \\ Section: Healthcare \\ Transient Hearing Loss in Patients after Surgery Under Spinal Anaesthesia: A Tertiary Care Centre Based Study
} ISI Impact Factor (2019-20): 1.628 IC Value (2019): 90.81 SJIF (2020) $=7.893$

(c) (7) (8)

Copyright@IJCRR

\section{Aparna Girish Benare, Aditya Khot}

'Associate Professor, Department of Anesthesiology, Prakash Institute of Medical Sciences and Research, 1slampur-415409, Maharashtra, India.

\section{ABSTRACT}

Introduction: In most of the surgical interventions, spinal route of anaesthesia is the very frequent type of regional anaesthesia \& it's been used for with minimal complications. But few cases report hearing loss post-spinal anaesthesia, mostly affecting the low range frequency.

Objective: To study the post-spinal anaesthesia hearing loss observed in the patient at a tertiary care centre.

Method: The current study was done in a total of 60 cases who went for surgical intervention under spinal anaesthesia. Informed written consent was obtained from each patient. The pre-anaesthetic check-up was done in all the cases. Audiometry was done in all the cases before surgery. Post-operative hearing loss was recorded on $2^{\text {nd }}$ and $5^{\text {th }}$ day after surgery. The audiogram was done again after 1 month of surgery to verify whether hearing loss is temporary or permanent. Also resulting complications if any have been recorded.

Results: Maximum cases (40\%) in our study were in the age group of 21-30 years followed by 31-40 years of age. Majority of them were male $(60 \%)$ and $90 \%$ of patients were of the American Society of anaesthesiologists (ASA grade I. Temporary hearing loss was diagnosed in $13.33 \%$ cases. Post spinal headache was observed in $16.67 \%$ cases and post-spinal hypotension was observed in $23.33 \%$ cases. Two cases were having a hearing loss at $2000 \mathrm{~Hz}$ while at $250 \mathrm{~Hz}$ and $6000 \mathrm{~Hz}$ one case each was diagnosed. This hearing loss was completely revered in one month.

Conclusion: Transient hearing loss was diagnosed in $13.33 \%$ patients and it was found that hearing loss was completely reversible.

Key Words: Hearing loss, Spinal anaesthesia, Audiogram, Surgical intervention, Hearing loss

\section{INTRODUCTION}

In a tertiary care centre, many people undergo surgical intervention for some of the other reason. Every individual wants this experience to be painless both during the surgery \& afterwards. Spinal anaesthesia is the most commonly preferred method for its minimal complications. ${ }^{1,2}$ Its advantages are many like, it's a very cost-effective technique, need for intubation is not there and hence, in turn, there is no risk of aspiration pneumonia due to gastric contents. But this procedure is for the shorter duration only (up to two hours). Hearing loss after spinal anaesthesia has been well-known complication yet it's infrequently documented \& it affects mostly the lower frequency range. ${ }^{3,4}$
Such hearing disorders after spinal anaesthesia is frequently linked with the "postspinal headache syndrome". These clinical symptoms result from Cerebrospinal fluid (CSF) leakage via the spinal puncture hole. In turn, this CSF loss leads to a corresponding reduction in intracranial and intracochlear pressure. Spinal needle size can be associated with the occurrence of hearing loss. ${ }^{5,6}$ Besides, the auditory symptoms may be the result of drainage of inner ear fluid (perilymph) via the cochlear aqueduct that links CSF and cochlear fluids. Apart from that, there is a long list of post-surgical complications ranging from lumbar headache, vertigo, nausea, vomiting etc. Apart from spinal anaesthesia, there are many clinical scenarios where transient hearing loss can occur like myelography, acoustic neuroma surgeries, VP shunts, neurosurgeries etc..$^{7-9}$

\section{Corresponding Author:}

Dr. Aditya Khot, Associate Professor, Department of Anesthesiology, Prakash Institute of Medical Sciences and Research, Islampur-415409, Maharashtra, India.

ISSN: 2231-2196 (Print) ISSN: 0975-5241 (Online)
Received: 15.08 .2020
Revised: 06.10 .2020
Accepted: 12.11 .2020
Published: 16.01 .2021 


\section{MATERIALS AND METHODS}

The current study was performed at a tertiary care centre with the following inclusion \& exclusion criteria for selection of the study population:

\section{Inclusion Criteria}

- Patients admitted for various surgeries under spinal anaesthesia.

- Patients from the age group of 20 to 60 years.

- Patients with Normal hearing power.

- Patients in ASA grade I or II classifications.

\section{Exclusion Criteria}

- Patients not willing for Spinal anaesthesia or nervous or very apprehensive patients

- Patients with pre-existing hearing impairment.

- Patients with ASA grade III or more.

So finally, a total of 60 cases was selected for the study. Informed written consent was obtained from each patient. The pre-anaesthetic examination was done in all the patients. Detailed physical examination was carried out. The spine was examined to see the presence of any skin infection, deformity, calcification, movements and history of the previous operation. Audiometry was performed in all the patients before surgery in a sound-proArphi portable audiometer. Post-operative hearing loss was recorded on $2^{\text {nd }} \& 5^{\text {th }}$ day following surgery. The audiogram was repeated after onemonth post-surgery to verify if the return of normal hearing power had occurred. The complications that have occurred had also been recorded. All the findings were recorded on a Preformed proforma.

\section{RESULTS}

It was observed that the majority of the patients (40\%) in our study were in the age range of 21 to 30 years followed by 31 40 years of age $(26.67 \%)$. Majority of the patients were male $(60 \%)$ and $90 \%$ of patients were of ASA grade I (Table 1).

Table 1: Age, sex and ASA grade wise distribution

\begin{tabular}{lccc} 
& & No. of patients & $\%$ \\
Age group & $21-30$ & 24 & 40.00 \\
& $31-40$ & 16 & 26.67 \\
& $41-50$ & 12 & 20.00 \\
Sex & $51-60$ & 8 & 13.33 \\
\multirow{2}{*}{ ASA grade } & Male & 32 & 60.00 \\
& Female & 24 & 40.00 \\
& I & 54 & 90.00 \\
\hline
\end{tabular}

The mean preoperative systolic blood pressure was $126.45 \pm 12.78$ and mean post-operative systolic blood pressure was $114.65 \pm 12.38 \mathrm{~mm}$ of $\mathrm{Hg}$. The mean pre and postoperative diastolic blood pressure were $82.21 \pm 8.43$ and $61.93 \pm 7.34 \mathrm{~mm}$ of $\mathrm{Hg}$ respectively (Table 2 ).

\begin{tabular}{lccc}
$\begin{array}{l}\text { Table 2: Distribution according to Haemodynamic } \\
\text { changes }\end{array}$ & $\begin{array}{c}\text { Systolic } \\
\text { blood } \\
\text { pressure } \\
(\mathrm{mmHg})\end{array}$ & $\begin{array}{c}\text { Diastolic } \\
\text { blood } \\
\text { pressure } \\
(\mathrm{mmHg})\end{array}$ & $\begin{array}{c}\text { Mean arterial } \\
\text { Pressure } \\
(\mathrm{mmHg})\end{array}$ \\
\hline Pre-Operative & $126.45 \pm 12.78$ & $82.21 \pm 8.43$ & $82.36 \pm 4.68$ \\
Post-Operative & $114.65 \pm 12.38$ & $61.93 \pm 7.34$ & $76.34 \pm 5.74$ \\
\hline
\end{tabular}

Eight cases showed a transient hearing loss, ten cases showed post-spinal headache while fourteen cases had post-spinal hypotension ( Table 3 ).

\begin{tabular}{lcc} 
Table 3: Distribution according to complications \\
\hline & No. of patients & $\%$ \\
\hline Transient hearing loss & 8 & 13.33 \\
Post spinal headache & 10 & 16.67 \\
Post spinal hypotension & 14 & 23.33 \\
\hline
\end{tabular}

In our study, we have observed that four cases were having a hearing loss at $2000 \mathrm{~Hz}$ while at $250 \mathrm{~Hz} \& 6000 \mathrm{~Hz}$, two cases each were having hearing loss. All the cases were strictly followed for a month \& we found out that, this hearing loss was completely reversed after one month (Table 4).

Table 4: Distribution according to patients with significant hearing loss

\begin{tabular}{lcc} 
Frequency hertz $(\mathrm{Hz})$ & No. of patients & $\%$ \\
125 & 0 & 0.00 \\
250 & 2 & 3.33 \\
500 & 0 & 0.00 \\
1000 & 0 & 0.00 \\
2000 & 4 & 6.67 \\
4000 & 0 & 0.00 \\
6000 & 2 & 3.33 \\
8000 & 0 & 0.00 \\
Total & 8 & 13.33 \\
\hline
\end{tabular}

\section{DISCUSSION}

The current study was conducted at a tertiary care centre with the main objective was to study the post-spinal anaesthesia 
hearing loss observed in patients. We found out that the maximum cases in our study group were in the age group of 31-40 years (Table 1) \& the majority of them were males..$^{10,11}$ Ninety per cent of the cases were of ASA grade I. similar findings were observed by the previous studies. The average preoperative systolic blood pressure (BP) was $126.45 \pm 12.78$ \& mean postoperative systolic BP was $114.65 \pm 12.38 \mathrm{~mm}$ of $\mathrm{Hg}$. The average pre \& post-operative diastolic BP was $82.21 \pm 8.43 \& 61.93 \pm 7.34 \mathrm{~mm}$ of $\mathrm{Hg}$ (Table 2). Temporary hearing loss was diagnosed in $13.33 \%$ of the cases (Table 3 ).

Lumbar headache after spinal anaesthesia was seen in $16.67 \%$ of the cases whereas post-spinal hypotension was seen in $23.33 \%$ of the cases. Sirsamkar in their study observed that $8 \%$ of cases were suffering from temporary hearing loss. Whereas Lasisi ${ }^{12}$ observed that bone conduction hearing impairment after spinal anaesthesia was around $15 \%$. In a study conducted by Yildiz et al. ${ }^{13}, 7.5 \%$ of the study population reported the hearing impairment. In our research, it was observed that four cases were having a hearing loss at $2000 \mathrm{~Hz}$ while at $250 \mathrm{~Hz}$ and $6000 \mathrm{~Hz}$ two cases each was diagnosed (Table 4). All the study subjects were followed for a month and it was observed that the hearing loss was revered in one month. Bansode et al. ${ }^{10}$ in their study observed significant hearing impairment in overall $7.7 \%$ of their study subjects after spinal anaesthesia.

In Group Y (young) of their study 2 patients $(6.6 \%)$ developed significant hearing loss at $1000 \mathrm{~Hz}$. In groups M (middle-aged) 4 patients (13.3\%) had significant hearing loss. One developed hearing loss at $125 \mathrm{~Hz}$ while the other 3 patients had hearing loss at $6000 \mathrm{~Hz}$ and $8000 \mathrm{~Hz}$ (Table 4). In group E (elderly) only one patient (3.3\%) developed significant hearing loss at $250 \mathrm{~Hz}$. Wang et al. conducted a similar study and their findings are in agreement with our study findings.

Many researchers have suggested that there a strong association between post-dural puncture headache $\&$ this transient hearing loss. ${ }^{14-16}$ They say that both these conditions i.e postdural puncture headache \& transient hearing loss have the same mechanism which is drop-in intracranial tension due to Cerebrospinal fluid (CSF) leak. Hughson et al. ${ }^{17}$ say that a drop in CSF pressure predisposes to the decrease in intralabyrinthine pressure which ultimately results in transient hearing loss.

\section{CONCLUSION}

From the observations of our study, we can conclude that transient hearing loss was diagnosed in $13.33 \%$ patients and it was found that hearing loss was completely reversible. And the strong association between post-dural puncture headache $\&$ this transient hearing loss.

\section{ACKNOWLEDGEMENT}

Authors acknowledge the immense help received from the scholars whose articles are cited and included in references to this manuscript. The authors are also grateful to authors / editors / publishers of all those articles, journals, and books from which the literature for this article has been reviewed and discussed.

Ethical clearance: Taken from the institutional ethics committee.

\section{Conflict of Interest: Nil}

\section{Source of Funding: Nil}

\section{REFERENCES}

1. Walsted A. Effects of cerebrospinal fluid loss on hearing. Acta Otolaryngol 2000; 543:95-98.

2. Lee C. Hearing loss after spinal anaesthesia. Anesth Analg 1990;71:561-569.

3. Rajan R, Gosavi SN, Dhakate V, Ninave S. A Comparative Study of Equipotent Doses of Intrathecal Clonidine and Dexmedetomidine on Characteristics of Bupivacaine Spinal Anesthesia. J Datta Meghe Inst Med Sci Uni 2018;13(1); 4-8.

4. Finegold H. Does Spinal Anesthesia Cause Hearing Loss in the Obstetric Population? Anesth Analg 2002; 95:198-203.

5. Hafer J. The effect of needle type and immobilization on postspinal headache. Anaesthesist 1997;46:860-866.

6. Sarma JP, Narayana S, Ganapathi P, Shivakumar MC. A comparative study of intrathecal clonidine and dexmedetomidine on characteristics of bupivacaine spinal block for lower limb surgeries. Anesth Essays Res 2015;9(2):195-207.

7. Schaffartzik W. Hearing loss after spinal and general anesthesia: A comparative study. Anesth Analg 2000;91:1466-1472.

8. Malhotra S. Spinal analgesia and auditory functions: a comparison of two sizes of Quinoke needles. Minerve Anaesthesiol 2007; 73: 395-399.

9. Palan A, Agrawal NK. Control of Intraoperative Shivering under Spinal Anaesthesia- A Prospective Randomized Comparative Study of Butorphanol with Tramadol. J Krishna Inst Med Sci Uni 2017; 6(1): 57-65.

10. Bansode A. Age comparative study on spinal anaesthesia and auditory functions. J Evol Med Dent Sci 2012;1(6):1026-1033.

11. Nefissa M. Hearing Loss after Spinal Anaesthesia: A Too Little Appreciated Complication? Med J Cairo Univ 2014; 82(1): 321-329.

12. Lasisi A. Effect of Spinal Anaesthesia on Hearing Threshold. East Central Afric J Surg 2010;15(2):80-84.

13. Yildiz T. Hearing loss after spinal anaesthesia: the effect of different infusion solutions. Otolaryngol Head Neck Surg 2007;137:79-82.

14. Planning B. Transient low-frequency hearing loss following spinal anaesthesia (in German) Anaesthetist 1984;33:593-595.

15. Vandan L. Long term follow up of patients who received 10098 spinal anaesthetics JAMA 1956;161:586-591.

16. Arnvig J. A transient hearing loss after a lumbar puncture - A personal experience which throws some light on aqueduct of cochlea. Acta Otolaryngol 1963:56:699-705.

17. Hughson SA. A note on the relationship between cerebrospinal fluid and intralabyrinthine pressure. Ame J Phys 1932;101:396407. 